\title{
metabolites
}

ISSN 2218-1989

www.mdpi.com/journal/metabolites/

Article

\section{Isolation and Expression of a cDNA Encoding Methylmalonic Aciduria Type A Protein from Euglena gracilis $\mathbf{Z}$}

\section{Yukinori Yabuta, Ryota Takamatsu, Satoshi Kasagaki and Fumio Watanabe *}

School of Agricultural, Biological, and Environmental Sciences, Faculty of Agriculture, Tottori University, 4-101 Koyama-Minami, Tottori 680-8553, Japan;

E-Mails: yabuta@muses.tottori-u.ac.jp (Y.Y.); ascorbate250@gmail.com (R.T.); cobalaminb12@gmail.com (S.K.)

* Author to whom correspondence should be addressed; E-Mail: watanabe@muses.tottori-u.ac.jp; Tel.: +81-857-31-5412; Fax: +81-857-31-5412.

Received: 27 December 2012; in revised form: 6 February 2013 / Accepted: 7 February 2013 / Published: 18 February 2013

\begin{abstract}
In animals, cobalamin $(\mathrm{Cbl})$ is a cofactor for methionine synthase and methylmalonyl-CoA mutase (MCM), which utilizes methylcobalamin and 5'-deoxyadenosylcobalamin (AdoCbl), respectively. The cblA complementation class of inborn errors of $\mathrm{Cbl}$ metabolism in humans is one of three known disorders that affect AdoCbl synthesis. The gene responsible for cblA has been identified in humans $(M M A A)$ as well as its homolog (meaB) in Methylobacterium extorquens. Recently, it has been reported that human MMAA plays an important role in the protection and reactivation of MCM in vitro. However, the physiological function of $M M A A$ is largely unknown. In the present study, we isolated the cDNA encoding MMAA from Euglena gracilis Z, a photosynthetic flagellate. The deduced amino acid sequence of the cDNA shows 79\%, 79\%, 79\% and 80\% similarity to human, mouse, Danio rerio MMAAs and $M$. extorquens MeaB, respectively. The level of the MCM transcript was higher in Cbl-deficient cultures of E. gracilis than in those supplemented with Cbl. In contrast, no significant differences were observed in the levels of the MMAA transcript under the same two conditions. No significant difference in MCM activity was observed between Escherichia coli that expressed either MCM together with $M M A A$ or expressed MCM alone.
\end{abstract}

Keywords: cobalamin; Euglena gracilis; methylmalonyl-CoA mutase; MMAA; vitamin $\mathrm{B}_{12}$ 


\section{Introduction}

Vitamin $\mathrm{B}_{12}$, or cobalamin $(\mathrm{Cbl})$, is an organometallic cofactor that supports the activities of enzymes in organisms, ranging from bacteria to humans [1,2]. In animals, $\mathrm{Cbl}$ is the cofactor for cytosolic methionine synthase (EC 2.1.1.13) and mitochondrial methylmalonyl-CoA mutase (MCM, EC 5.4.99.2), more specifically, methylcobalamin (MeCbl) and 5'-deoxyadenosylcobalamin (AdoCbl), respectively. Inhibition of $\mathrm{Cbl}$ transport or biochemical modifications of $\mathrm{Cbl}$ usually causes severe diseases [3]. The $c b l A$ complementation class of inborn errors of $\mathrm{Cbl}$ metabolism is one of three known disorders that affect AdoCbl synthesis without affecting the synthesis of $\mathrm{MeCbl}$ [4]. The gene responsible for $c b l A$ has been identified through the examination of prokaryotic gene arrangements and is called MMAA [3]. The deduced amino acid sequences of human or mouse MMAA show homology with the periplasmic protein kinase ArgK of Escherichia coli [3]. ArgK is a coupled ATPase of the lysine, arginine and ornithine (LAO) transport system [5], suggesting the possibility that MMAA is a component of a transporter or an accessory protein that is involved in the translocation of $\mathrm{Cbl}$ into mitochondria [3].

MCM and a homolog of MMAA (MeaB) are present in the genome of the methylotrophic bacterium Methylobacterium extorquens AM1 [6]. This bacterium synthesizes AdoCbl and utilizes AdoCbl as the cofactor for MCM and meaA (ethylmalonyl-CoA mutase). The mutation in meaB has no effect on the function of meaA. However, total MCM activity was significantly reduced in meaB mutants compared with that of the wild-type, although the meaB mutants synthesized AdoCbl [7]. These findings suggest that meaB is not involved in the biosynthesis of $\mathrm{AdoCbl}$ or the transport of $\mathrm{Cbl}$ in M. extorquens.

Diol and glycerol dehydratases, Cbl-dependent enzymes, undergo concomitant irreversible inactivation by glycerol during catalysis [8]. This inactivation involves irreversible cleavage of the Co-C bond of AdoCbl, forming 5'-deoxyadenosine and an alkylcobalamin-like species. The Cbl species that is formed remains tightly bound to the enzyme, inactivating the enzyme irreversibly. Diol or glycerol dehydratase-reactivating factor participates in reactivation of the inactivated holoenzymes by mediating ATP-dependent exchange of the modified coenzyme for free intact coenzyme [9-12].

Korokova and Lidstrom [7] found that meaB forms a complex with MCM and stimulates MCM activity in vitro. However, neither cyanocobalamin $(\mathrm{CNCbl})$ nor $\mathrm{AdoCbl}$ is released from $\mathrm{MCM}$ in the presence of meaB. Further, purified meaB did not restore MCM activity in the extracts prepared from the meaB mutant. Therefore, they proposed that meaB does not function as a reactivating factor, but is involved in protection of MCM from suicide inactivation by possibly providing a stabilization function. However, recently, it has been reported that meaB involved in AdoCbl trafficking to MCM functions as an editor, discriminating between inactive and active cofactor forms and permitting transfer only of AdoCbl, in a process that is gated by GTP hydrolysis [13]. Furthermore, the editing function of $m e a B$ is also used for reactivating inactivated MCM formed occasionally during turnover. Takahashi-Íñiguez et al. [14] have reported that human MMAA plays as two important roles as both the "protectase" and reactivase of MCM. In E. coli, sleeping beauty mutase (sbm; MCM homolog) interacts with $y g f D$ (the $M M A A$ or meaB homolog) [15].

Euglena gracilis Z, a photosynthetic flagellate, possesses characteristics of both plant and animal cells [16] and requires $\mathrm{Cbl}$ for its growth [17,18]. It has been reported that E. gracilis has Cbl-dependent methionine synthase and ribonucleotide redactase [19,20]. Furthermore, the purification 
of aquacobalamin reductase form E. gracilis was reported [21]. Recently, we reported that E. gracilis MCM is a homodimer and is present in mitochondria [22]. Further, we isolated a full-length E. gracilis MCM cDNA whose deduced amino acid sequence indicates that it is a mitochondrial protein. These findings suggest the possibility that E. gracilis, human and M. extorquens MCMs share molecular properties. To explore the function of $M M A A$, we isolated a cDNA encoding MMAA from E. gracilis and measured MCM activity in E. coli that expressed MCM alone or together with MMAA.

\section{Results and Discussion}

\subsection{Isolation and Characterization of a cDNA Encoding MMAA}

To isolate a cDNA encoding E. gracilis MMAA, a BLASTP search was performed against the Euglena EST data base [23] using the amino acid sequence of human $M M A A$ [3] as a query. This search revealed an EST clone (cluster ID ELL00001639) encoding a putative E. gracilis MMAA. Similar to other $M M A A$ or $m e a B$, this EST clone is annotated as a putative periplasmic protein kinase ArgK. The corresponding full-length cDNA was cloned using the rapid amplification of cDNA ends method, and its sequence was submitted to the DDBJ/GenBank/EMBL data base (accession number AB772316). In E. gracilis, the short sequences present at the 5' end of small cytoplasmic mRNAs [24-26] are transferred to pre-mature mRNAs by a trans-splicing mechanism. The presence of a spliced leader sequence at the 5' end of E. gracilis MMAA cDNA (5'-TTTTTTTTCG-3') indicated that full-length $M M A A$ cDNA was obtained. The cDNA contains $1,400 \mathrm{bp}$ with an open reading frame of 1,056 bp predicted to encode 352 amino acids residues (with a calculated molecular mass of $39113.9 \mathrm{Da}$ ).

The deduced amino acid sequence of the E. gracilis $M M A A$ cDNA shows $79 \%, 79 \%, 79 \%$ and $80 \%$ similarity to human (NP_758454), mouse (NP_598584), Danio rerio (NP_001098582) MMAAs and $M$. extorquens (AAL86727) meaB, respectively (Figure 1). The E. gracilis MMAA cDNA encodes a predicted protein of 352 amino acid residues and includes Walker A and Walker B motifs, as well as a GTP-binding sequence [3]. The presence of a signal peptide and cleavage sites was predicted by the TargetP prediction program [27]. However, the cleavage site is present in the relatively well-conserved region among the $M M A A s$ of vertebrates (Figure 1), suggesting the possibility that the $M M A A$ cleavage site in $E$. gracilis is located closer to its $\mathrm{N}$-terminal region.

\subsection{Expression of MMAA by E. gracilis}

Although it is known that the levels of MCM protein and total MCM activity in the livers of Cbl-deficient rats are higher than those in the livers of rats whose diet was supplemented with Cbl, the level of the MCM transcript in the livers of rats fed a Cbl-deficient diet was lower than that in the livers of rats fed Cbl-supplemented diets [28]. To explore the regulation of the expression of $M C M$ and $M M A A$, we analyzed the levels of their respective transcripts in response to $\mathrm{Cbl}$ in Cbl-deficient $E$. gracilis.

Cells cultured $(1 \mathrm{~mL})$ for one week were transferred to CNCbl-free medium, cultured for another week and then transferred $(1 \mathrm{~mL})$ to $\mathrm{CNCbl}$-free medium. After three days, $\mathrm{CNCbl}(5 \mu \mathrm{g} / \mathrm{mL})$ was added, and the cells were cultured for another three days (closed circles; Figure 2). Under the Cbl deficient condition, the growth of E. gracilis cells was highly suppressed (open circles; Figure 2). The addition of $\mathrm{CNCbl}$ increased the cell growth. 
Figure 1. Comparison of the deduced amino acid sequences of $M M A A$ from E. gracilis, human, mouse, D. rerio and meaB from $M$. extorquens. Sequences were aligned using ClustalW [29]. Sequence motifs defining the G3E family of proteins are indicated, including the GxxGxGK[S/T] Walker A and the DHbHbHbHbE Walker B motif. Hb denotes hydrophobic residues and an [N/T]KxD GTP-binding motif, as described by Leipe et al. [30], is underlined. Red letters indicate the mitochondrial leader sequence. Amino acids that are identical in all species are shaded gray.

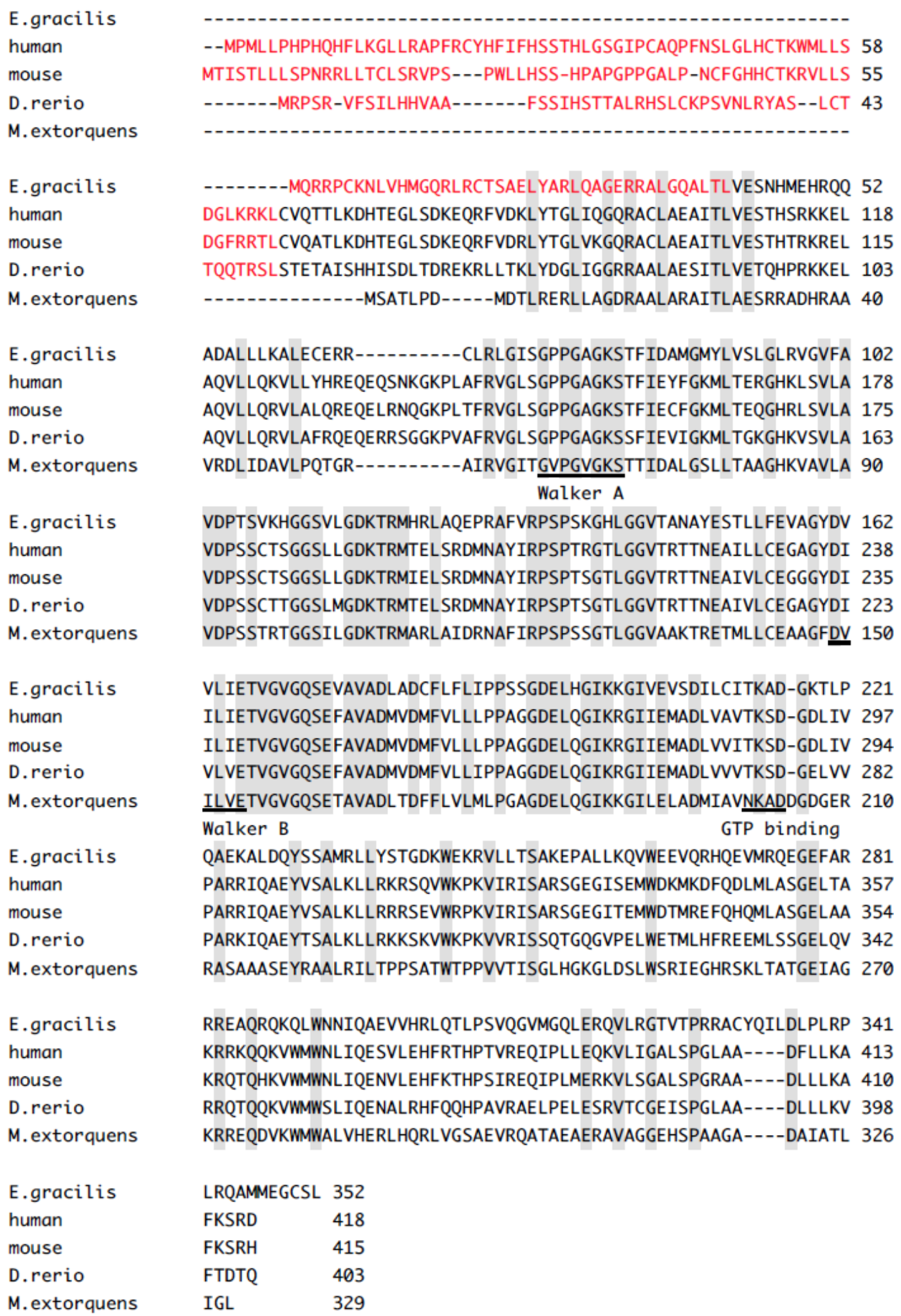


Figure 2. Effect of the addition of $\mathrm{CNCbl}$ on the growth of Cbl-deficient E. gracilis cells. Open circles are Cbl-deficient cells. Closed circles are Cbl-supplemented cells. The data are the mean value $\pm \mathrm{SD}$ of three individual experiments. Asterisks indicate that the mean values are significantly different compared with those of Cbl-deficient E. gracilis cells $(p<0.05)$.

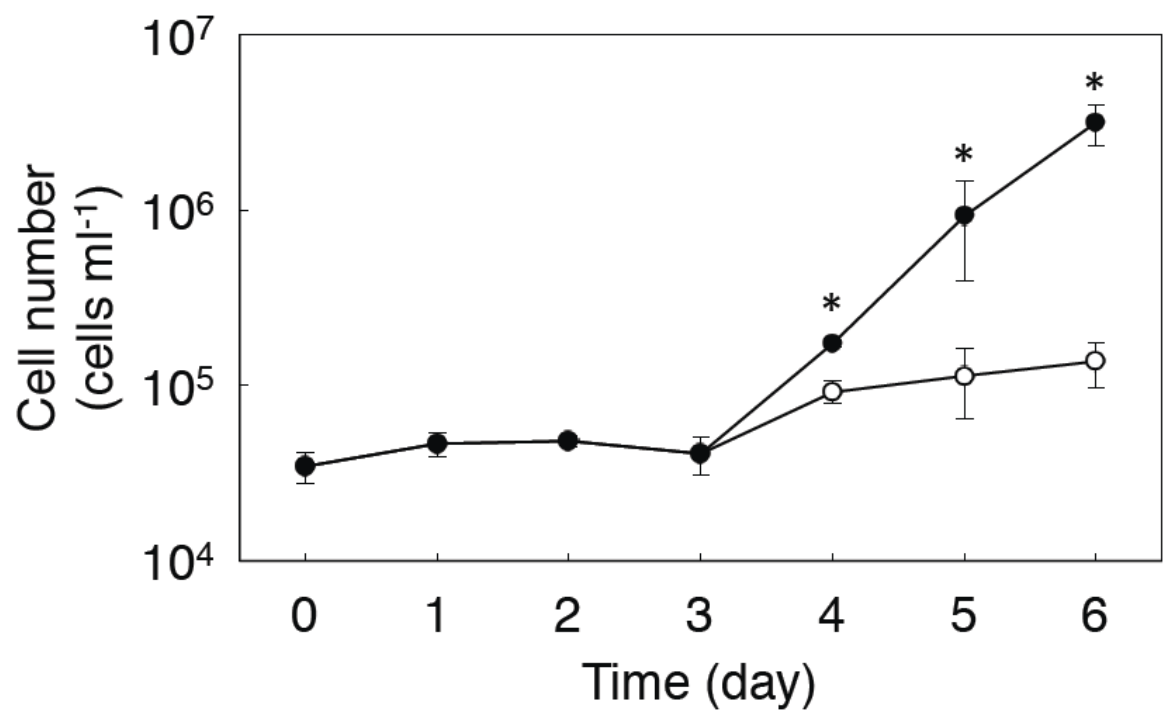

In three-day cultured Cbl-deficient E. gracilis cells, total MCM activity was $8.54 \mathrm{nmol} \mathrm{min}{ }^{-1} \mathrm{mg}^{-1}$ protein. At three days after the addition of $\mathrm{Cbl}$ to Cbl-deficient cells, total MCM activity was decreased to $38 \%$, while that in the Cbl-deficient cells remained high (89\%). In Cbl-deficient E. gracilis cells, the level of the MCM transcript was 2.3-fold higher than that in the Cbl-supplemented E. gracilis cells (Figure 3).

In contrast, no significant differences in the levels of the $M M A A$ transcript were observed between the Cbl-deficient and Cbl-supplemented E. gracilis, suggesting the possibility that $M M A A$ is constitutively expressed these cells.

Figure 3. Semi-quantitative real-time (RT)-PCR analysis of the levels of $M C M$ and $M M A A$ transcripts in (1) Cbl-deficient and (2) Cbl-supplemented E. gracilis cultures. Fragments corresponding to $M C M, M M A A$, and EF 1- $\alpha$ were amplified using PCR.

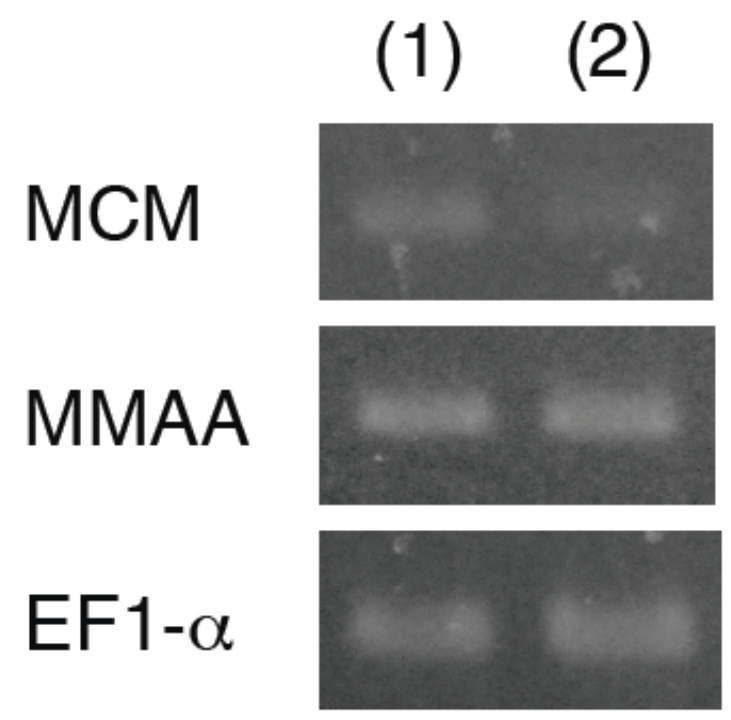




\subsection{Effect of Coexpression of MMAA on MCM Activity in E. coli}

As noted above, $M C M$ activity is significantly decreased in meaB mutants of $M$. extorquens [7]. To examine the effect of the expression of $M M A A$ on $M C M$ activity, the expression vectors pET/Eg.MCM and $\mathrm{pCDF} /$ Eg.MMAA were transformed together or individually in $E$. coli using the expression vectors described below. In cells transformed with either the combinations of pET-16b and pCDF/Eg.MMAA or pET-16b and pCDF-1b, MCM activity was below the detection limit of the assay (5 pmol $\mathrm{min}^{-1} \mathrm{mg}^{-1}$ protein) (Table 1). No significant difference in $M C M$ activity was detected between cells expressing $M C M$ alone or together with $M M A A$. We checked E. gracilis MMAA protein in E. coli cells using anti His-tag antibody. E. gracilis MMAA protein was slightly expressed in the soluble fraction in the pCDF-1b/Eg.MMAA transformed E. coli, suggesting that the expression level of E. gracilis MMAA protein was very low.

Table 1. $M C M$ activity in E. coli expressing $M C M$ or $M M A A$ together or individually.

\begin{tabular}{cc}
\hline Vector pairs & MCM activity (nmol $\mathbf{~ m i n}^{-\mathbf{1}} \mathbf{~ m}^{\mathbf{- 1}}$ protein) $^{-1}$ \\
\hline pET/Eg.MCM - pCDF-1b & $12.1 \pm 2.0$ \\
pET-16b - pCDF-1b/Eg.MMAA & $<0.005$ \\
pET-16b - pCDF-1b & $<0.005$ \\
pET/Eg.MCM - pCDF/Eg.MMAA & $11.6 \pm 1.8$ \\
\hline
\end{tabular}

Data are mean values \pm standard deviation from three assays.

E. coli $s b m$ and $y g f D$ genes are contained in an operon comprising sbm-ygfD-ygfG-ygfH [31]. E. coli sbm forms a homodimer [14] as its E. gracilis homolog. Further, the deduced amino acid sequence of E. coli $\mathrm{sbm}$ is $89 \%$ similar to that of E. gracilis MCM. These findings suggest the possibility that $y g f D$ functions to protect $E$. gracilis $M C M$ from inactivation and acts to reactivate it in E. coli. Previous findings, and our presented data suggests the possibility that the function of E. gracilis MMAA was similar to those of human $M M A A$ and meaB.

In Caenorhabditis elegans, the suppression of $M M A A, M M A B$ [co(I)balamin adenosyltransferase] or $M C M$ expression using RNAi technology caused the increase of methylmalonic acid [32]. To clarify the $\mathrm{Cbl}$ metabolism, including the function of $M M A A$ in E. gracilis, analyses using recombinant proteins and RNAi technology are necessary.

\section{Experimental Section}

\subsection{E. gracilis and Culture Conditions}

E. gracilis strain $Z$ was grown in Koren-Hutner medium under continuous illumination at a photosynthetic photon flux density of $24 \mu \mathrm{mol} \mathrm{m} \mathrm{m}^{-2} \mathrm{~s}^{-1}$ at $26{ }^{\circ} \mathrm{C}$ until the cells reached stationary phase (6 days) [33]

\subsection{RT-PCR-Amplification and Sequence Analysis}

Based on analysis of the Euglena EST database using the Protest EST Program [23], a gene-specific primer was designed to amplify the missing $3^{\prime}$ and $5^{\prime}$ ends of the MMAA EST sequence 
(ELL00001639). Total RNA was isolated from E. gracilis using Sepasol-RNA I (Nakalai Tesque, Kyoto, Japan). The primers 5'-TGGTGGAGTCAAACCACATG-3' and 5'- TCAGACACTTCCACAATGCC -3' were used sequentially for 3'-rapid amplification of cDNA ends (3'-RACE) or 5'-RACE with a GeneRacer $^{\text {TM }}$ Kit (Life Technologies, Carlsbad, CA, USA). Amplified fragments were cloned into pSTBlue-1, and the nucleotide sequences of the 3'- or 5'-extended fragments were determined using an ABI Prism 3100 Genetic Analyzer (Applied Biosystems, Foster City, CA, USA). The full-length coding sequence of Euglena MMAA was amplified using PCR primed by Eg.MMAA-F (5'-ATTCCATGCAACGCCGCCCA-3') and Eg.MMAA-R (5'-CCACGTATGCTTTCCTCCTT-3'). PCR amplification was carried out using PrimeSTAR (Takara Shuzo, Kyoto, Japan). A single-stranded cDNA prepared from 3-day Euglena cultures was used as template. The amplified product was cloned into pZErO-2 (Life Technologies), and the sequence was verified using an ABI Prism 3100 Genetic Analyzer (Applied Biosystems).

\subsection{Semi-Quantitative RT-PCR Analysis}

Semi-quantitative RT-PCR analysis was performed according to Ishikawa et al. [22]. Primer pairs were as follows: EF1- $\alpha-\mathrm{F}$ (5'-GTTGACCCTCATTGGTGCTT-3'); EF1- $\alpha-\mathrm{R}$ (5'-CTTGGTCACCTTCCCAGTGT-3'); Eg.MCM-F (5'-GTCCATCGACAACACCATTG -3'); Eg.MCM-R (5'-CGACTTCAGCTCGTTGATGA -3'); and Eg.MMAA-F (5'-ATTCCATGCAAC GCCGCCCA-3'); Eg.MMAA-R (5'-TCAGACACTTCCACAATGCC-3'). The experiments were repeated at least three times with cDNA prepared from three batches of E. gracilis cultures. The quantitative intensity was determined by applying densitometry to images of the blots [34].

\subsection{Construction of MMAA and MCM Expression Plasmids}

To construct $M M A A$ and $M C M$ expression vectors, their open reading frames were amplified from the first strand cDNAs, using the primer sets as follows: MMAA-Pma CI-F (5'-TCACCACC ACCATCACGTGATGCAACGCCGCCCATGCAA-3'), MMAA-Pma CI-R (5'-TCGAACCGGTAC CCACGTGCTACAGGCTGCAGCCCTCCA-3'), MCM-Nde I-F (5'-CATATGATCGACCTTCCA CCAAAGTG-3') and MCM-Bam HI-F(5'-GGATCCTCAGAGTTTGTTCAGGACCT-3'). The amplified DNA fragments were ligated into the vector pZErO-2 (Life Technologies), and the sequence was verified using an ABI Prism 3100 Genetic Analyzer (Applied Biosystems). The resulting constructs were digested with Pma CI for MMAA or Nde I/Bam HI for MCM and ligated into the expression vectors pCDF-1b (Novagen, Madison, WI) or pET16b (Novagen) to produce histidine-tagged proteins. The resulting constructs were designated pCDF/Eg.MMAA and pET/Eg.MCM, respectively.

\subsection{Expression of Recombinant MMAA or MCM Proteins}

To explore the effect of the expression of Eg.MMAA on MCA activity in E. coli, four plasmids sets (pET16-b and pCDF-1b, pET/Eg.MCM and pCDF-1b, pET16-b and pCDF/Eg.MMAA and pET/Eg.MCM and pCDF/Eg.MMAA) were introduced into E. coli strain BL21 Star (DE3) (Life Technologies). Transformed E. coli were cultured in $50 \mathrm{~mL}$ LB medium supplemented with ampicillin $\left(50 \mu \mathrm{g} \mathrm{mL}^{-1}\right)$ and chloramphenicol $\left(34 \mu \mathrm{g} \mathrm{mL}^{-1}\right)$ at $37{ }^{\circ} \mathrm{C}$ overnight. The culture was then 
transferred to Luria-Bertani medium (1 1). When the culture reached an absorbance of 0.6 at $600 \mathrm{~nm}$, $0.4 \mathrm{mM}$ isopropyl $\beta$-D-thiogalactopyranoside was added, and the bacteria were grown for another $6 \mathrm{~h}$ at $37^{\circ} \mathrm{C}$. The cells were harvested by centrifugation at $6,000 \times \mathrm{g}$ for $10 \mathrm{~min}$, and the pellets were kept frozen at $-20^{\circ} \mathrm{C}$.

\subsection{Enzyme Extraction and Assay}

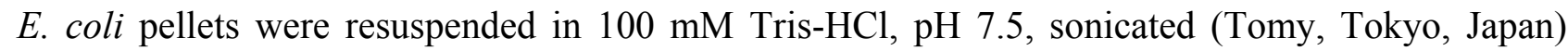
$(10 \mathrm{kHz})$ using $20 \mathrm{~s}$ strokes with $30 \mathrm{~s}$ intervals and centrifuged at $15,000 \times \mathrm{g}$ for $15 \mathrm{~min}$. MCM activity was assayed by a modified HPLC method described by Gaire et al. (1999). Briefly, the assay mixture $(0.15 \mathrm{~mL})$ for determining total $M C M$ activity contained $100 \mathrm{mM}$ potassium phosphate buffer (pH 7.5), $30 \mu \mathrm{M}$ AdoCbl, $0.15 \mathrm{mM}(R, S)$-methylmalonyl-CoA and enzyme. The components, except for $(R, S)$-methylmalonyl-CoA, were mixed in microcentrifuge tubes in the dark, and the temperature was equilibrated by incubation in a heating bucket (e-Heating Bucket EHB, TAITEC Cop., Saitama, Japan) maintained at $3{ }^{\circ} \mathrm{C}$. The reaction mixture was preincubated for $5 \mathrm{~min}$, and the reaction was started by the addition of $(R, S)$-methylmalonyl-CoA and maintained for $5 \mathrm{~min}$. The enzyme reaction was stopped by the addition of $50 \mu \mathrm{L}$ of $10 \%(\mathrm{w} / \mathrm{v})$ trichloroacetic acid. The reaction mixture was filtered through a $0.45 \mu \mathrm{M}$ membrane filter (Millex Syringe Driven Filter Unit, LH-type, Milli-pore, USA). An aliquot $(20 \mu \mathrm{L})$ of the filtrate was analyzed using a Shimadzu HPLC apparatus (two LC-10ADvp pumps, DGV-12A degasser, SCL-10Avp system controller, SPD-10Avvp ultraviolet-visible detector, CTO-10Avp column oven, $100 \mu \mathrm{L}$ sample loop and C-R6A Chromatopac Integrator). The sample $(20 \mu \mathrm{L})$ was loaded onto a reversed-phase HPLC column (Cosmosil 5C18-AR-II, $\Phi 3.0 \times 150 \mathrm{~mm})$ equilibrated with $50 \%$ solvent $\mathrm{A}(100 \mathrm{mM}$ acetic acid in $100 \mathrm{mM}$ potassium phosphate buffer, $\mathrm{pH} 7.0)$ and $50 \%$ solvent $\mathrm{B}[18 \%(\mathrm{v} / \mathrm{v})$ methanol in solvent $\mathrm{A}]$. $(R, S)$-methylmalonyl-CoA and succinyl-CoA were eluted with a linear gradient of methanol (50\%-100\% solvent B) for $7.0 \mathrm{~min}$ at $40{ }^{\circ} \mathrm{C}$ and monitored by measuring the absorbance at $254 \mathrm{~nm}$.

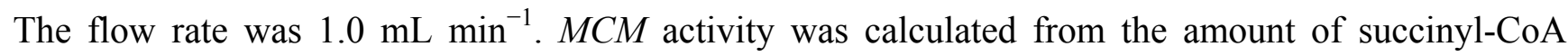
formed. Protein concentrations were determination using a Quant-iT ${ }^{\text {TM }}$ Protein Assay and a Qubit fluorometer (Life Technologies).

\section{Conclusion}

E. gracilis $M M A A$ cDNA contained an open reading frame encoding the protein of 352 amino acids with a calculated molecular mass of $39113.9 \mathrm{Da}$, preceded by a putative mitochondrial targeting signal consisting of 41 amino acid residues. No significant differences in the levels of the MMAA transcript were observed between the Cbl-deficient and Cbl-supplemented E. gracilis. No significant difference in MCM activity was observed between E. coli that expressed either MCM together with MMAA or expressed MCM alone. Previous findings, and our presented data suggests the possibility that the function of E. gracilis $M M A A$ was similar to those of human $M M A A$ and meaB.

\section{Acknowledgments}

The authors would like to thank Enago [35] for the English language review. 


\section{Conflict of Interest}

The authors declare no conflict of interest.

\section{References}

1. Banerjee, R.; Ragsdale, S.W. The many faces of vitamin $\mathrm{B}_{12}$ : Catalysis by cobalamin-dependent enzymes. Annu. Rev. Biochem. 2003, 72, 209-247.

2. Ueta, K.; Ishihara, Y.; Yabuta, Y.; Masuda, S.; Watanabe, F. TLC-analysis of a corrinoid compound from Japanese rock-oyster "Iwa-gaki" (Crassostrea. nippona). J. Liquid Chromatography Related Technol. 2011, 34, 928-935.

3. Dobson, C.M.; Wai, T.; Leclerc, D.; Wilson, A.; Wu, X.; Doré, C.; Hudson, T.; Rosenblatt, D.S.; Gravel, R.A. Identification of the gene responsible for the cblA complementation group of vitamin $\mathrm{B}_{12}$-responsive methylmalonic acidemia based on analysis of prokaryotic gene arrangements. Proc. Natl. Acad. Sci. USA 2002, 99, 15554-15559.

4. Lerner-Ellis, J.P.; Dobson, C.M.; Wai, T.; Watkins, D.; Tirone, J.C.; Leclerc, D.; Doré, C.; Lepage, P.; Gravel, R.A.; Rosenblatt, D.S. Mutations in the MMAA gene in patients with the cblA disorder of vitamin $\mathrm{B}_{12}$ metabolism. Hum. Mutat. 2004, 6, 509-516.

5. Celis, R.T.; Leadlay, P.F.; Roy, I.; Hansen, A. Phosphorylation of the periplasmic binding protein in two transport systems for arginine incorporation in Escherichia coli $\mathrm{K}-12$ is unrelated to the function of the transport system. J. Bacteriol. 1998, 180, 4828-4833.

6. Korotkova, N.; Chistoserdova, L.; Kuksa, V.; Lidstrom, M.E. Glyoxylate regeneration pathway in the methylotroph Methylobacterium. extorquens AM1. J. Bacteriol. 2002, 184, 1750-1758.

7. Korotkova, N.; Lidstrom, M.E. MeaB is a component of the methylmalonyl-CoA mutase complex required for protection of the enzyme from inactivation. J. Biol. Chem. 2004, 279, 13652-13658.

8. Toraya, $\mathrm{T}$. Radical catalysis of $\mathrm{B}_{12}$ enzymes: structure, mechanism, inactivation, and reactivation of diol and glycerol dehydratases. Cell. Mol. Life Sci. 2000, 57, 106-127.

9. Mori, K.; Tobimatsu, T.; Toraya, T. A protein factor is essential for in situ reactivation of glycerol-inactivated adenosylcobalamin-dependent diol dehydratase. Biosci. Biotechnol. Biochem. 1997, 61, 1729-1733.

10. Mori, K.; Tobimatsu, T.; Hara, T.; Toraya, T. Characterization, sequencing, and expression of the genes encoding a reactivating factor for glycerol-inactivated adenosylcobalamin-dependent diol dehydratase. J. Biol. Chem. 1997, 272, 32034-32041.

11. Toraya, T.; Mori, K. A reactivating factor for coenzyme $\mathrm{B}_{12}$-dependent diol dehydratase. J. Biol. Chem. 1999, 274, 3372-3377.

12. Kajiura, H.; Mori, K.; Tobimatsu, T.; Toraya, T. Characterization and mechanism of action of a reactivating factor for adenosylcobalamin-dependent glycerol dehydratase. J. Biol. Chem. 2001, 276, 36514-36519.

13. Padovani, D.; Banerjee, R. A G-protein editor gates coenzyme $\mathrm{B}_{12}$ loading and is corrupted in methylmalonic aciduria. Proc. Natl. Acad. Sci. USA 2009, 106, 21567-21572. 
14. Takahashi-Íñiguez, T.; García-Arellano, H.; Trujillo-Roldán, M.A.; Flores, M.E. Protection and reactivation of human methylmalonyl-CoA mutase by MMAA protein. Biochem. Biophys. Res. Commun. 2011, 404, 443-447.

15. Froese, D.S.; Dobson, C.M.; White, A.P.; Wu, X.; Padovani, D.; Banerjee, R.; Haller, T.; Gerlt, J.A.; Surette, M.G.; Gravel, R.A. Sleeping beauty mutase (sbm) is expressed and interacts with ygfd in Escherichia coli. Microbiol. Res. 2009, 164, 1-8.

16. Kitaoka, S.; Nakano, Y.; Miyatake, K.; Yokota, A. In The Biology of Euglena; Buetow, D.E., Ed.; Academic Press: San Diego, CA, USA, 1989; Volume 4, pp. 1-135.

17. Isegawa, Y.; Nakano, Y.; Kitaoka, S. Conversion and distribution of cobalamin in Euglena gracilis $\mathrm{Z}$, with special reference to its location and probable function within chloroplasts. Plant Physiol. 1984, 76, 814-818.

18. Watanabe, F.; Nakano, Y.; Stupperich, E. Different corrinoid specificities for cell growth and the cobalamin uptake system in Euglena gracilis Z. J. Gen. Microbiol. 1992, 138, 1807-1813.

19. Isegawa, Y.; Watanabe, F.; Kitaoka, S.; Nakano, Y. SubcelluIar distribution of cobalamin-dependent methionine synthase in Euglena gracilis z. Phytochemisty. 1994, 35, 59-61

20. Torrents, E.; Trevisiol, C.; Rotte, C.; Hellman, U.; Martin, W.; Reichard, P. Euglena gracilis ribonucleotide reductase: the eukaryote class II enzyme and the possible antiquity of eukaryote $\mathrm{B}_{12}$ dependence. J. Biol. Chem. 2006, 281, 5604-5611.

21. Watanabe, F.; Oki, Y.; Nakano, Y.; Kitaoka, S. Purification and characterization of aquacobalamin reductase (NADPH) from Euglena gracilis. J. Biol. Chem. 1987, 262, 11514-11518.

22. Miyamoto, E.; Tanioka, Y.; Nishizawa-Yokoi, A.; Yabuta, Y.; Ohnishi, K.; Misono, H.; Shigeoka, S.; Nakano, Y.; Watanabe, F. Characterization of methylmalonyl-CoA mutase involved in the propionate photoassimilation of Euglena gracilis Z. Arch. Microbiol. 2010, 192, 437-446.

23. Taxonomically Broad EST Database. Available online: http:/amoebidia.bcm.umontreal.ca/pepdb/searches/login.php

24. Tessier, L.H.; Keller, M.; Chan, R.L.; Fournier, R.; Weil, J.H.; Imbault, P. Short leader sequences may be transferred from small RNAs to pre-mature mRNA by trans-splicing in Euglena. EMBO J. 1991, 10, 2621-2625.

25. Frantz, C.; Ebel, C.; Paulus, F.; Imbaut, P. Characterization of trans-splicing in Euglenoids. Curr. Genet. 2000, 37, 349-355.

26. Ishikawa, T.; Tajima, N.; Nishikawa, H.; Gao, Y.; Rapolu, M.; Shibata, H.; Sawa, Y.; Shigeoka, S. Euglena gracilis ascorbate peroxidase forms an intramolecular dimeric structure: its unique molecular characterization. Biochem. J. 2010, 426, 125-134.

27. TargetP prediction program. Available online: http://www.cbs.dtu.dk/services/TargetP/

28. Nakao, M.; Hironaka, S.; Harada, N.; Adachi, T.; Bito, T.; Yabuta, Y.; Watanabe, F.; Miura, T.; Yamaji, R.; Inui, H.; Nakano, Y. Cobalamin deficiency results in an abnormal increase in L-methylmalonyl-co-enzyme-A mutase expression in rat liver and COS-7 cells. Br. J. Nutr. 2009, 101, 492-498.

29. ClustalW Program. Available online: http://clustalw.ddbj.nig.ac.jp/index.php?lang=ja, accessed on 10 February 2013.

30. Leipe, D.; Wolf, Y.; Koonin, E.; Aravind, L. Classification and evolution of P-loop GTPases and related ATPases. J. Mol. Biol. 2002, 317, 41-72. 
31. Haller, T.; Buckel, T.; Rétey, J.; Gerlt, J.A. Discovering new enzymes and metabolic pathways: conversion of succinate to propionate by Escherichia coli. Biochemistry 2000, 39, 4622-4629.

32. Chandler, R.J.; Aswani, V.; Tsai, M.S.; Falk, M.; Wehrli, N.; Stabler, S.; Allen, R.; Sedensky, M.; Kazazian, H.H.; Venditti, C.P. Propionyl-CoA and adenosylcobalamin metabolism in Caenorhabditis. elegans: Evidence for a role of methylmalonyl-CoA epimerase in intermediary metabolism. Mol. Genet. MeTable 2006, 89, 64-73.

33. Koren, L.E.; Hutner, S.H. High-yield media for photosynthesizing Euglena gracilis Z. J. Protozool. 1967, 14, 17.

34. Image J. Available online: http://rsbweb.nih.gov/ij/, accessed on 10 February 2013.

35. Enago. Available online: http://www.enago.jp/, accessed on 10 February 2013.

(C) 2013 by the authors; licensee MDPI, Basel, Switzerland. This article is an open access article distributed under the terms and conditions of the Creative Commons Attribution license (http://creativecommons.org/licenses/by/3.0/). 